\title{
VARIABILIDADE HIDROLÓGICA NAS BACIAS DOS RIOS AGUAPEÍ E PEIXE, REGIÃO OESTE PAULISTA
}

\author{
ROCHA, Paulo Cesar - pcrocha@fct.unesp.br \\ FCT/UNESP/GAIA \\ TOMMASELLI, Jose Tadeu Garcia - tadeu@fct.unesp.br \\ FCT/UNESP/GAIA
}

\begin{abstract}
RESUMO. Este trabalho aborda o comportamento hidrológico nas bacias dos rios Aguapeí e Peixe, que drenam parte da região do Planalto Ocidental Paulista. Para tanto, foram avaliados o regime hidrológico dos rios, a precipitação, as condicionantes de uso e ocupação da área e a evolução do processo de desmatamento nas bacias. A obtenção dos regimes fluviométrico e pluviométrico foram baseados em dados diários, mensais e anuais de séries históricas. Os resultados indicam que houveram significativas variabilidades nos regimes hidrológicos dos rios Aguapeí e Peixe ao longo da série avaliada e as alterações mais significativas se deram a partir da década de 1970. Estas alterações no regime hidrológico dos dois rios parecem estar relacionadas a dois fatores: 1) alteração no regime pluviométrico; e 2) processos de desmatamento e transformação da cobertura vegetal natural, que até a década de 1970, já haviam ocorrido na maior parte da área.
\end{abstract}

Palavras-chave: Variabilidade Hidrológica; Desmatamento; Bacia Hidrográfica; Rio Aguapeí; Rio do Peixe HYDROLOGIC VARIABILITY IN THE AGUAPEİ AND PEIXE BASINS, WEST REGION OF SÃO PAULO

\begin{abstract}
This paper discusses the hydrological behavior in the Aguapeí and Peixe river basins, which drain the Western Plateau region of São Paulo State. Therefore it was evaluated the hydrological regime of rivers, precipitation, the constrains in use and occupation of the area and the evolution of the deforestation process in both basins. The achievement of mean fluvial and rainfall regimes were based upon daily data and monthly and annual historical series. The results indicate that there were significant variability in hydrologic regimes of Aguapeí and Peixe Rivers throughout the evaluated series and the most significant changes happened after the 1970s. These changes in the hydrological regime of both rivers seems to be related to two factors: 1) change in mean rainfall regime; and 2) deforestation and transformation processes of natural vegetation cover, which until the 1970s, had already occurred in most of the area.
\end{abstract}

Keywords: hydrological variability; deforestation; drainage basin; Aguapeí River; Peixe River

\section{INTRODUÇÃO}

A água doce pode ser considerada individualmente o mais importante recurso da humanidade. Em escala mundial, uma das causas inibidoras da expansão da agricultura e do povoamento de vastas regiões é a insuficiência da água. Em escala local, os recursos hídricos determinam a localização de certas indústrias e a geração de energia. Antigamente, o estabelecimento de povoações estava em relação estreita com a localização de rios e fontes. As povoações dos oásis oferecem um exemplo desse processo (DREW, 1994).

A bacia hidrográfica pode ser considerada, em linhas gerais, um sistema físico onde a entrada de água é o volume precipitado e a saída é o volume de água escoado pelo exutório e a água evapotranspirada. Em termos gerais, ela provê uma unidade física bem definida para estudos hidrológicos, tendo uma única forma de entrada (input), a precipitação, e a saída é dada pelo runoff na exutória da bacia, consideradas as perdas por evapotranspiração. Em macroescala, como no caso de grandes bacias hidrográficas, o padrão de runoff e suas intensidades e sazonalidades poderão ser controlados, primariamente, pelos efeitos climáticos. Este padrão geral reflete os padrões de precipitação e circulação geral da atmosfera. Para comparação entre bacias hidrográficas individuais, a geologia, morfometria da bacia, solos e vegetação, assim como os aspectos climáticos, interagem entre si para determinar o padrão natural sazonal de variação de runoff (PETTS \& FOSTER, 1990).

Atualmente reconhece-se que o desflorestamento, as práticas de uso da terra agrícola e urbana, a utilização da água subterrânea para abastecimento e irrigação, além da construção de grandes barramentos para abastecimento e, principalmente, para geração de energia, 
somadas, geram um efeito bola-de-neve e contribui para alterações no ciclo e regime hidrológicos dos rios. Além deste, outros aspectos relacionados à drenagem entram em desequilíbrio, como os ecossistemas terrestres e aquáticos e a dinâmica erosivo-deposicional nas vertentes e nos canais fluviais.

O desenvolvimento da agricultura e da sociedade organizada sempre esteve vinculado ao controle da água, especialmente para irrigação. As civilizações do antigo Egito e da China, assim como da Índia e da Mesopotâmia, chamam-se civilizações hidráulicas. Sua ascensão e queda estiveram intimamente relacionadas ao uso e abuso da água. A intromissão no ciclo hidrológico continua até o presente. Com o avanço da tecnologia, o grau de interferência aumentou de maneira vertiginosa. Atualmente, são poucos os sistemas de drenagem, no mundo inteiro, que tem caráter inteiramente natural. Embora o controle dos sistemas hidrológicos seja maior nos países desenvolvidos, as modificações inadvertidas nestes sistemas são universais, em geral em função do atual modelo de apropriação da natureza pelo homem contemporâneo (DREW, 1994).

As intervenções humanas no ciclo hidrológico se dão em diferentes pontos (ou fases do ciclo). Segundo Drew (1994), pode-se imaginar o ciclo hidrológico como uma série de armazenagens de água ligadas por transferências. De fato, muitos depósitos são na realidade transferências mais demoradas (por exemplo, da água subterrânea) e algumas transferências mais rápidas (por exemplo, os rios) também exercem limitada função de armazenagem. Em cada ponto de intervenção, diferentes podem ser as intensidades dos impactos. Geralmente os maiores impactos estão associados às intervenções na infiltração, na armazenagem e nos fluxos fluviais.

Normalmente, o desmatamento ou o desflorestamento exerce considerável efeito nas perdas de água. A perda de cobertura arbórea, em curto prazo, reduz a perda de água do solo por transpiração, pois as raízes profundas das árvores são arrancadas, bem como provoca maior escoamento das águas na superfície do solo, visto que a antiga manta amortecedora de folhas caídas foi substituída pela terra nua. Assim, o mais provável é o aumento do fluxo direto da água para os rios. A figura 1 ilustra o efeito do desmatamento no fluxo fluvial de pequenas bacias hidrográficas.
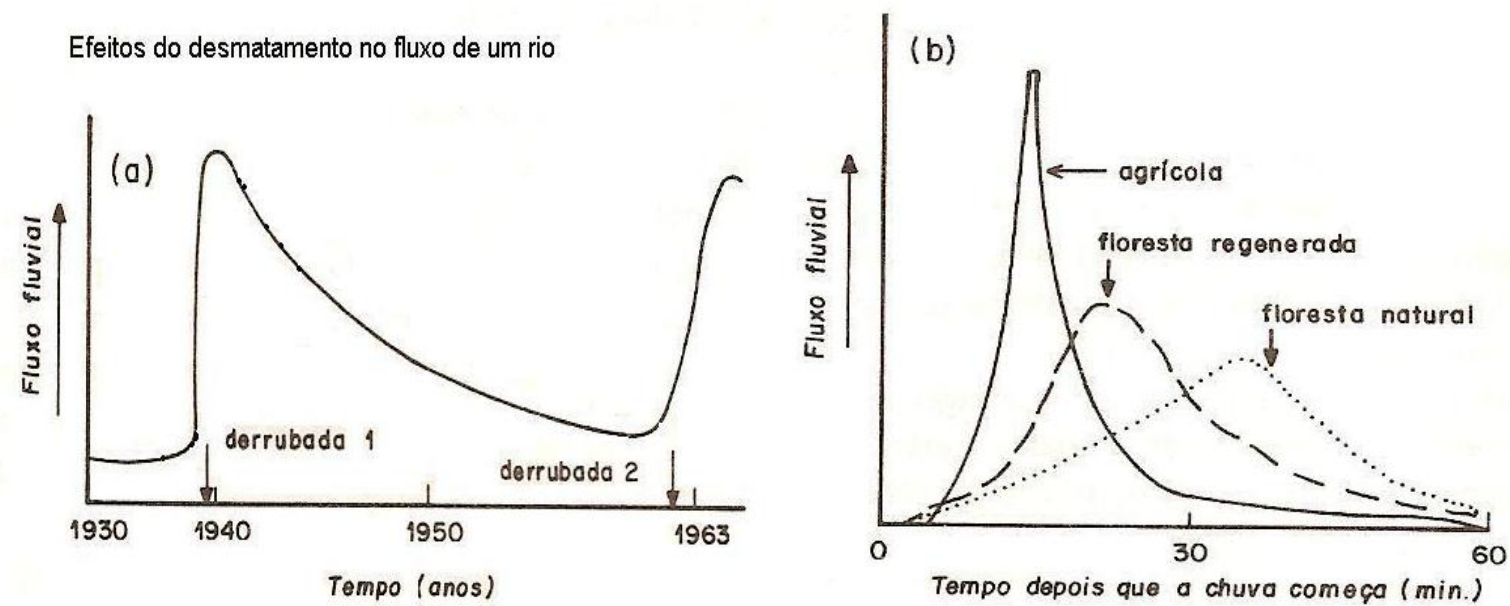

Figura 1. Efeitos do desmatamento no fluxo de um rio. Em (a) alteração do fluxo fluvial após o desmatamento. Em (b) os diferentes hidrogramas após a chuva em bacias da mesma área com diferentes usos do solo. Conforme Drew (1994).

Tendo em vista a intensa apropriação dos recursos fluviais pelo homem, existe uma crescente necessidade de prever os impactos ambientais associados ao manejo dos corpos de água, identificar metas a serem atingidas para manter a biota fluvial e os adequados valores sociais e de serviços associados com o ecossistema fluvial. Isso criou certa quantidade de novas 
disciplinas científicas de modelagem e descrição relativas aos canais fluviais. Vários estudos sobre as relações entre a variabilidade hidrológica e a integridade do ecossistema fluvial sugerem um paradigma do regime natural do rio: a completa variabilidade do regime hidrológico intra e inter-anual, e associada característica de periodicidade, duração, frequência e taxa de mudança, são críticas na sustentação da biodiversidade total nativa e integridade do ecossistema aquático (RICHTER et al., 1997).

Neste trabalho, foram utilizados os dados fluviométricos diários (descargas), mensais e anuais de estações fluviométricas com série histórica longa nos rios Aguapeí e Peixe (afluentes do Alto Rio Paraná),além de estimativas a partir de correlação entre as estações (figura 2), com o objetivo de se avaliar o comportamento hidrológico dos rios ao longo da série histórica avaliada e relacioná-lo com dados de precipitação e de cobertura da terra, na perspectiva da dinâmica temporal.

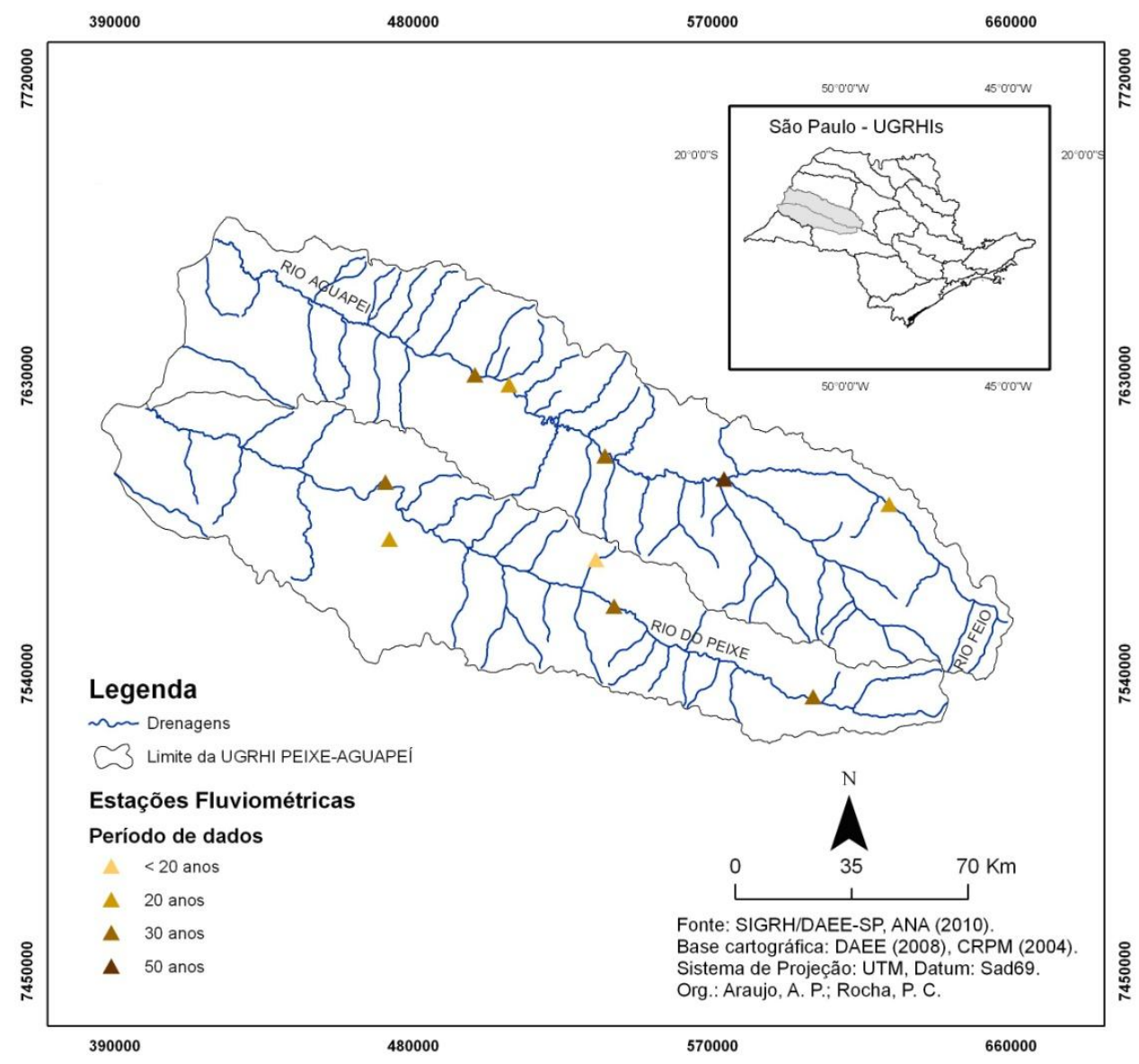

Figura 2. Localização da área de estudos.

\section{ESTUdOS PRÉVIOS NA BACIA DO ALTO RIO PARANÁ}

As investigações sobre o comportamento hidrológico dos rios da bacia do Alto Paraná para o entendimento das suas variabilidades hidrológicas e alterações no regime foram objeto de análises em diversas pesquisas, tais como Araujo et al. (2009); Clarke et al. (2003) e vários outros. Trabalhos prévios sobre as alterações hidrológicas associadas às mudanças na cobertura da terra e mudanças no regime pluviométrico foram abordados por Tucci \& Clarke (1998) e Collischonn et al. (2001) no rio Paraguai, e por Rocha et al. (1994, 1998, 2001, 
2003) e Rocha (2010) no rio Paraná; estes últimos associando também aos efeitos de grandes barragens.

De modo geral, os autores observaram uma nítida alteração de magnitude no regime hidrológico do alto rio Paraná a partir do início da década de 1970 (figura 3).

Estes autores associaram a alteração, em parte, ao efeito do controle de débitos pelas grandes barragens na bacia, e em parte, aos processos de uso e ocupação nas encostas. O primeiro efeito causa achatamento dos picos de máxima e mínima vazão (regulação); o segundo pode alterar a magnitude do fluxo.

Guaíra e Porto São José

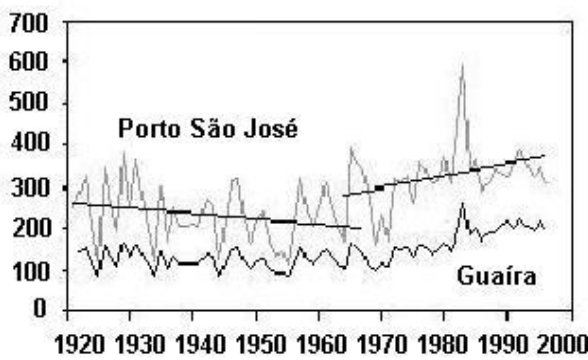

A

período

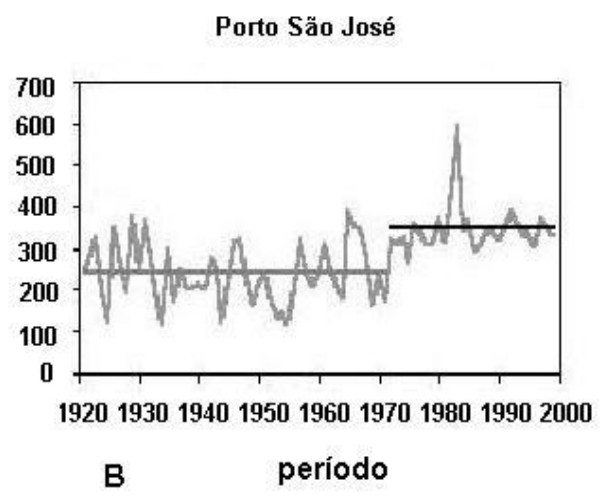

B

Figura 3. Cotas médias anuais e tendências para os dois períodos hidrológicos. Estação de Porto São José-PR e Guaíra-PR, médias (nível hidrométrico) dos períodos hidrológicos definidos (Fonte, Rocha et al., 1998, 2001, 2003).

\section{PROCEDIMENTOS METODOLÓGICOS}

Segundo Richter et al. (1997), as características do fluxo oferecem alguns dos mais usados e apropriados indicadores para se avaliar a integridade do ecossistema fluvial ao longo do tempo, devido a certas circunstâncias: 1) muitas outras características abióticas de ecossistemas fluviais variam com as condições do fluxo, incluindo os níveis de oxigênio dissolvido, temperatura da água, distribuição dos tamanhos dos sedimentos suspensos e de fundo, e estabilidade do leito do rio; 2) em grande escala, a morfologia do canal e da planície de inundação é formada por processos fluviais dirigidos pelo fluxo do rio, particularmente pelas condições de altos fluxos; 3 ) em contraste com a relativa falta de novidades e a grosseira resolução de séries temporais de dados biológicos, a disponibilidade de longas séries temporais de dados fluviométricos diários de rios muitos grandes ( $4^{\mathrm{a}}$ a $10^{\mathrm{a}}$ ordem) pode prover uma alta percepção a respeito da variabilidade natural e da história recente das perturbações associadas às ações antrópicas na bacia hidrográfica que repercutem nos rios.

O fluxo natural de um rio varia conforme a escala de tempo avaliada, na ordem de horas, dias, estações do ano, anos e adiante. No entanto, são necessários muitos anos de observação em uma estação fluviométrica para se descrever as características do padrão de fluxo de um rio, em termos de quantidade, periodicidade e variabilidade, que é o seu regime de fluxo natural. Em bacias hidrográficas que carecem de dados hidrológicos de série longa, as análises podem ser estendidas estatisticamente a partir de outra estação localizada na mesma área geográfica (POFF et al., 1997).

Foram mapeadas as estações fluviométricas com séries históricas longas em funcionamento e/ou que tiveram série longa de dados até recentemente, a partir de levantamento junto a 
Agência Nacional de Águas e ao Departamento Estadual de Águas de São Paulo/SIGRH. Posteriormente foi avaliada a localização das estações representativas e solicitados os dados hidrológicos diários, buscando contemplar os trechos alto, médio e baixo dos rios principais nas duas bacias escolhidas para análise. Para as estações com série histórica incompleta, os dados foram estimados a partir de correlacionamento (neste trabalho estabelecido para $\mathrm{R}^{2}$ maior que 0,7$)$ através de regressão linear simples entre estações dentro da mesma área geográfica, conforme preconizado por Poff et al. (1997).

A esse respeito, cabe lembrar que as duas bacias de drenagem correm por terrenos do mesmo domínio geológico - domínio dos arenitos do Grupo Bauru (IPT, 1981) e geomorfológico planalto ocidental paulista (ROSS e MOROZ, 1997), assim como pertencem à mesma região climática - clima tropical alternadamente seco e úmido (MONTEIRO, 1976), o que facilita a correlação entre os dados das estações.

Assim, a abordagem utilizada foi a dos Índices de Alteração Hidrológica (IAH), proposta por Poff et al. (1997). Essa metodologia é uma importante ferramenta para a execução de políticas públicas e tomadas de decisão que possibilitem a recuperação ambiental e sustentabilidade dos cursos d'água. É também um método que antecede os estudos e os cálculos para o estabelecimento do hidrograma ecológico.

Geralmente, os estudos sobre alterações hidrológicas dos rios se referem aos efeitos a jusante de uma determinada barragem. Contudo, este trabalho visa identificar a variabilidade interanual do fluxo e identificar possíveis alterações no regime hidrológico dos rios Aguapeí e Peixe, utilizando-se o índice (IAH) magnitude do fluxo (anual) (POFF et al., 1997; RICHTER et al., 1997). Para tanto foram utilizados os dados de médias anuais das séries hidrológicas das estações disponíveis para estas bacias.

Os dados de precipitação foram analisados qualitativamente, baseados nos comentários dos trabalhos de Monbeig (1984), Zavatini (1998) e Sant'Anna Neto (2000). Foram também utilizados, para análise quantitativa, os dados de precipitação de quatro estações pluviométricas com série longa de dados, em diferentes posições geográficas e diferentes altitudes ao longo das bacias em estudo. São elas: estações pluviométricas de Garça, Luziânia, Monte Castelo e Panorama, cujos dados estão disponibilizados on-line e acessados no site do DAEE/SIGRH-SP (Sistema de Gestão de Recursos Hídricos do Estado de São Paulo). Esses dados foram utilizados para fornecer uma análise preliminar do comportamento sazonal e interanual da precipitação total nos trechos alto, médio e baixo das bacias e no auxílio à identificação dos períodos hidrológicos.

Foram também levantados qualitativamente dados de cobertura da terra, baseado nos dados de desmatamento e avanço das frentes pioneiras na região Oeste Paulista, conforme os estudos de Monbeig (1984) e levantamento Cavalli et al.(1974) e da ONG RBMA (2007).

Desse modo serão, a seguir, discutidas as alterações na magnitude anual do fluxo (média anual) e as possíveis relações com a variabilidade pluviométrica e a dinâmica do desmatamento e uso da terra nas bacias. 


\section{RESULTADOS E DISCUSSÃO}

\section{A variabilidade interanual e sazonal dos rios Aguapeí e Peixe.}

O regime hidrológico dos dois rios em estudo pode ser observado na figura 4 e na tabela 1 . Os dois rios apresentam alteração nas suas magnitudes interanuais desde o início da década de 70, acompanhando o que apresentam os rios Paraná e Paraguai. O diferencial para o rio Paraná é que este ainda apresenta um achatamento dos picos de máxima e mínima desde o início da década de 70, que são atribuídos ao controle de fluxo pelos barramentos (UHEs) a montante que iniciaram a operação coincidentemente neste período em diante.

Porém, não foram observados apenas dois períodos hidrológicos, mas sim pelo menos três, considerando a série de dados utilizada. Um primeiro período até 1972; outro entre 1972 e 1987; outro a partir de 1988. Ainda é provável que este último período ou fase hidrológica tenha terminado em 2001 quando um novo período hidrológico possa ter começado, contudo a série de dados avaliada não permite melhor detalhamento.

Analisando-se os gráficos da figura 4 e os dados da tabela 1 , nota-se que os dois rios apresentam um mesmo comportamento hidrológico, corroborando a premissa de que pertençam à mesma região climática e hidrológica no Oeste Paulista.

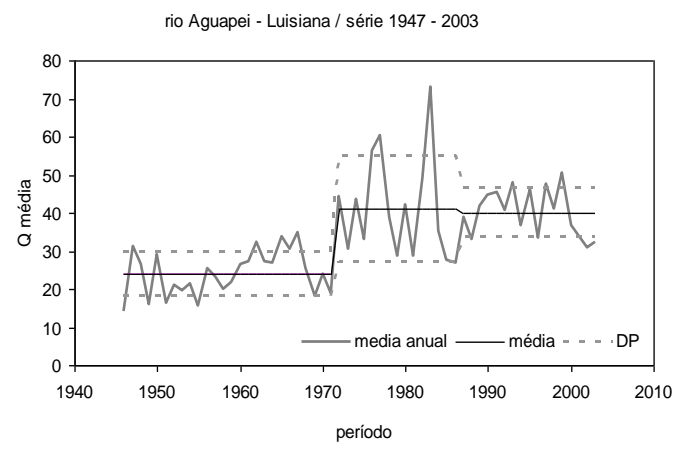

A

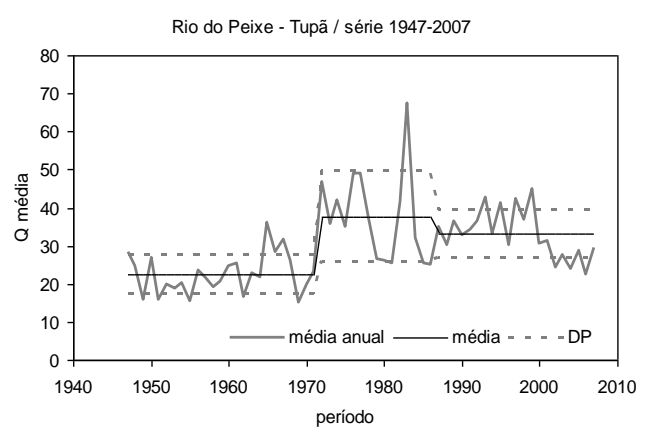

B

Figura 4. Variabilidade das vazões médias anuais e períodos hidrológicos identificados.

Quanto aos dados propriamente ditos, os gráficos indicam os três períodos hidrológicos mais nítidos. O primeiro caracterizado por menores valores de vazão, desvio padrão e coeficiente de variação que os valores da série completa dos dados. Isso significa menores magnitudes do fluxo e menor variabilidade interanual. O segundo período se caracteriza por apresentar os maiores valores médios de vazão, desvio padrão e coeficiente de variação do que os dados da série completa. Isso significa dizer que neste período ocorreram maiores magnitudes de fluxo e maior variabilidade interanual. O terceiro período é marcado por apresentar valores de vazão média também superiores à media da série completa, porém com valores de desvio padrão e do coeficiente de variação inferiores. Este período é marcado também por apresentar proximidade nos valores de média para com o período anterior, porém com menor variância. É o período que apresenta os menores valores do coeficiente de variação, considerando a série histórica e os períodos individualmente. 
Tabela 1.

Valores de média e desvio padrão das séries estudadas para as estações monitoradas.

\begin{tabular}{lcc}
\hline & Aguapeí & Peixe \\
\hline $\begin{array}{l}\text { Área de drenagem até a estação fluviométrica } \\
\left(\mathrm{km}^{2}\right)\end{array}$ & 3.670 & 2.883 \\
Qm série anual & $\mathbf{3 3 , 2}$ & $\mathbf{2 9 , 9}$ \\
Qm 1 & 24,1 & 22,5 \\
Qm 2 & 41,1 & 37,7 \\
Qm 3 & 40,1 & 33,1 \\
DP série anual & $\mathbf{1 1 , 9}$ & $\mathbf{1 0 , 0}$ \\
DP 1 & 5,8 & 5,3 \\
DP 2 & 13,6 & 12,0 \\
DP 3 & 6,3 & 6,3 \\
CV série anual & $\mathbf{3 5 , 7}$ & $\mathbf{3 3 , 4}$ \\
CV 1 & 24,2 & 23,6 \\
CV 2 & 33,2 & 31,9 \\
CV 3 & 15,6 & 19,0
\end{tabular}

Obs: dados obtidos dos valores da média anual de séries históricas entre as décadas de 1940 e 2000. Qm (vazões médias anuais); DP (desvio padrão da série); CV (coeficiente de variação em \%). Os valores 1, 2 e 3 indicam os três períodos hidrológicos identificados: 1 (1947-1971), 2 (1972-1987), 3 (após 1988).

Quanto às variações na sazonalidade, estas apresentam maiores valores nos dois últimos períodos observados (1972-1987, 1988-2004). Contudo, a variabilidade média mensal, considerando-se os valores do desvio padrão, apresentou semelhança entre o primeiro período e o terceiro período. Contudo, os valores de coeficiente de variação mostraram-se maiores no primeiro período do que no terceiro período.

Por outro lado, em termos de variabilidade do fluxo, os desvios padrão e coeficientes de variação calculados indicam que a variabilidade interanual do fluxo teve intensidade muito maior no segundo período hidrológico, que compreende 1972-1987.

Pode-se observar, ainda, que o segundo período, 1972-1987, apresentou sazonalidade no fluxo mais irregular, principalmente nos meses em que se esperava estiagem. Os valores de desvio padrão e de coeficiente de variação atestam esta afirmativa. Estes fatos ocorreram nos dois rios estudados, como mostra a figura 5.

\section{Avaliação do regime hidrológico: precipitação}

Na região de estudos, a pluviosidade e a vazão média anual de longo período (dados de 1985) são de $1.437 \mathrm{~mm}$ e 402 mm, respectivamente, com produção hídrica média anual de 12.540 
$\mathrm{m}^{3} / \mathrm{s}$, envolvendo as sub-bacias do Paraguai e do Paraná em território brasileiro (DCRH/DNAEE, 1985; em ZAVATINI, 1998).

A carta de isoietas anuais normais (período 31-60) do Atlas Climatológico da América do Sul (WMO/UNESCO, 1975, em ZAVATINI, op cit), demonstra que a pluviosidade na bacia do Paraná situava-se entre 1.200 e 1.600 mm, exceto no extremo oeste de Mato Grosso do Sul (Pantanal), onde os valores se reduzem $(1.000 / 1.200 \mathrm{~mm})$; no centro-sul do Paraná, no sudoeste de Minas Gerais e de Goiás $(2.000 \mathrm{~mm})$ e no curso superior do rio Paraná, onde se registraram índices mais fracos, entre 800 e $1.000 \mathrm{~mm}$. Segundo este autor, tais características praticamente se mantiveram com a mesma distribuição no período 1966/1985.

Recentemente, Sant'Anna Neto (2000) constatou tendência de aumento das chuvas no Estado de São Paulo, ao comparar os períodos 1941/1970 e 1971/1993, de aproximadamente $10 \%$ no segundo período, concentrados nos limites da bacia do Paraná. Observou pequena elevação nos valores pluviométricos e alteração na sazonalidade das chuvas na região de Presidente Prudente-SP, no Oeste Paulista, a partir da década de 1970.

Infelizmente, não foram feitos até o momento, trabalhos detalhados de regime pluviométrico que tome a bacia do Alto Rio Paraná por completo, fornecendo assim uma maior clareza nas informações históricas desta área, com base nas estações pluviométricas que possuam longas séries históricas, que são poucas, considerando a grandeza da área em estudo. Por isso, estudos em bacias menores podem ser importantes no sentido de abastecer um banco de dados.

Alguns estudos procuram entender as oscilações do regime hidrológico do rio Paraná, associando-as com as anomalias climáticas provocadas pelo ENOS (EI Niño Oscilação Sul), principalmente quanto aos altos fluxos, e os baixos fluxos à La Niña. Entretanto, tais abordagens não incorporam valores indicativos de ações antrópicas impactantes no regime fluvial do rio Paraná.

Mesmo considerando a possibilidade de aumento médio da pluviosidade na bacia do Paraná, tal fato, por si só, pode não explicar o conjunto de modificações ocorridas no regime hidrológico dos rios, como no caso do rio Paraná ao longo do último século, demonstrado por Rocha (2010). Porém, se tal possibilidade for verdadeira, é possível que as alterações relativas à magnitude dos índices fluviométricos estejam parcialmente acompanhando tal tendência e se somam aos efeitos do uso e ocupação das encostas e provocam alterações no regime hidrológico dos rios do Oeste Paulista. 

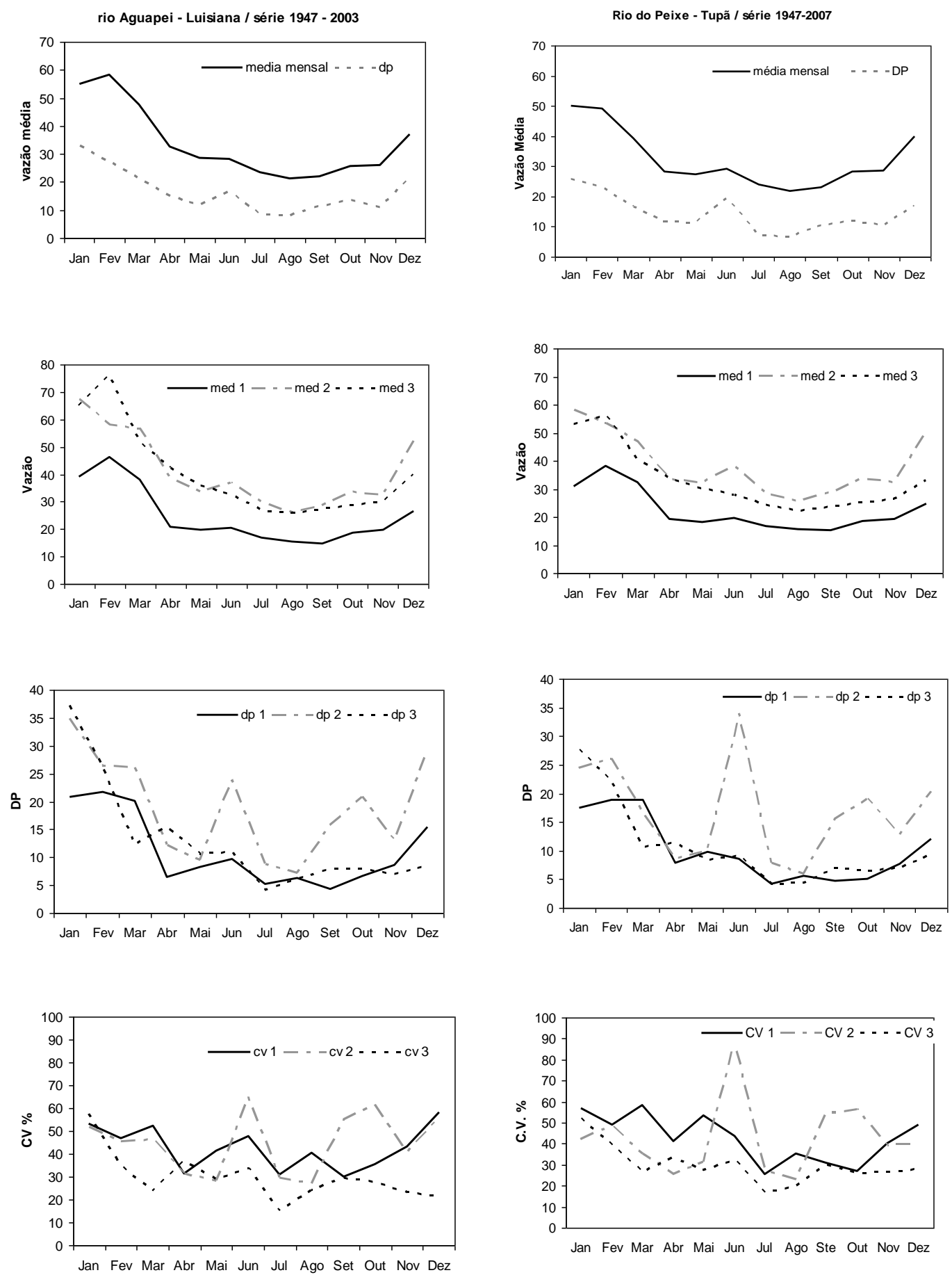

Figura 5. Estatística das variações sazonais ao longo da série histórica e dos períodos hidrológicos identificados. med: média, dp: desvio-padrão, CV: coeficiente de variação. !, 2 e 3 são os períodos referidos no texto: 1 (1947-1971), 2 (1972-1987), 3 (após 1988). 
As figuras 6 e 7 mostram os valores de pluviosidade anual e mensal em série histórica para as estações de Garça (680 m), Luiziânia $(420 \mathrm{~m})$, Monte Castelo (330 m) e Panorama (265 m), localizadas dentro dos limites das bacias aqui estudadas, no Oeste Paulista.

Considerando-se os valores totais interanuais, os períodos hidrológicos identificados nos dados fluviométricos não se apresentam com a mesma nitidez. Contudo, pode-se perceber em algumas das estações pluviométricas, como Garça (figura 6-A) e Luiziânia (figura 6-B) distintos períodos hidrológicos similares aos apresentados anteriormente.

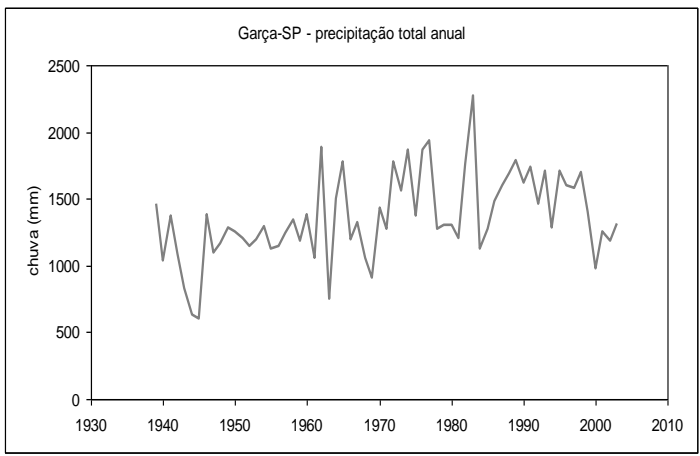

A

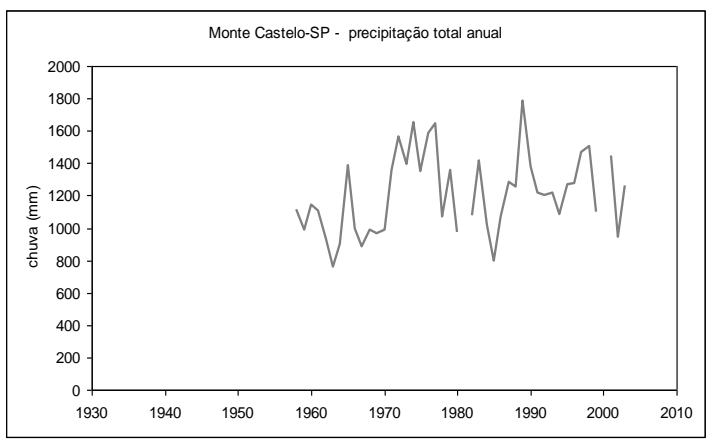

C

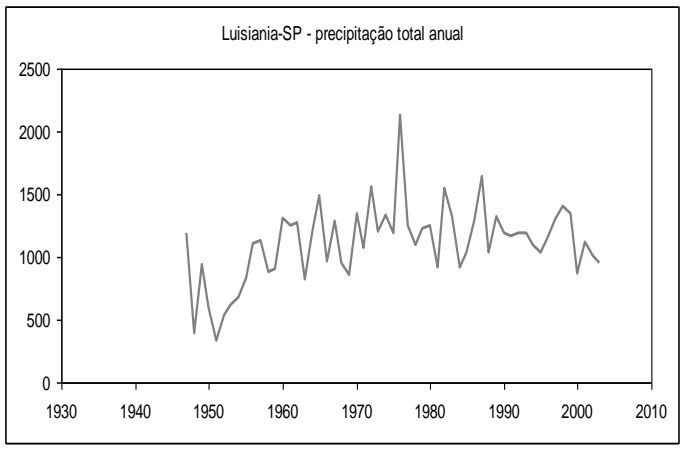

B

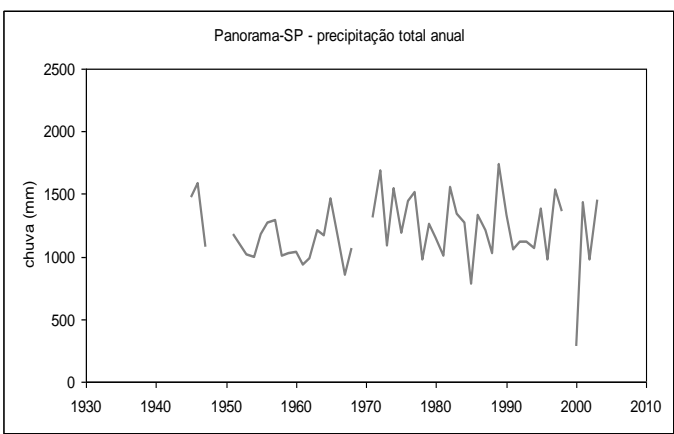

D

Figura 6. Precipitação total anual em Garça, Luiziânia, Monte Castelo e Panorama, oeste paulista. Trecho baixo, médio e alto das bacias hidrográficas, respectivamente.

Na figura 7, contudo, pode-se perceber mudanças na intensidade e sazonalidade das chuvas que também coincidem muito proximamente com os períodos anteriormente identificados. Observa-se que o verão foi se tornando mais úmido e o mês mais chuvoso se deslocou de dezembro-janeiro, para fevereiro-março ao longo das décadas. Por outro lado, houve intensificação do período de estiagem, também com deslocamento dos meses mais secos para o inverno e primavera, que anteriormente era mais úmida. Outros dados associados à dinâmica atmosférica no hemisfério sul também apontam para alternância de ciclos mais chuvosos e mais secos (associados a períodos mais quentes e mais frios respectivamente) (figura 8), como apontados por Molion (2008).

\section{As intervenções humanas no ciclo hidrológico}

$\mathrm{Na}$ bacia do Alto Paraná, as frentes de ocupação se deram de maneira diferenciada ao longo dos espaços, iniciando-se mais efetivamente pela região Sudeste da bacia, conforme sugere a 
figura 9, para o estado de São Paulo. Pode-se observar um grande avanço após a década de 1920 , advinda da ocupação pela cafeicultura que se expandia para o Oeste do estado. Durante a ocupação e o desmatamento, Monbeig (1984) cita relatos dos colonos durante os anos 1920 a 1940, que afirmavam que após o desmatamento da área era comum o aumento da água nas propriedades.

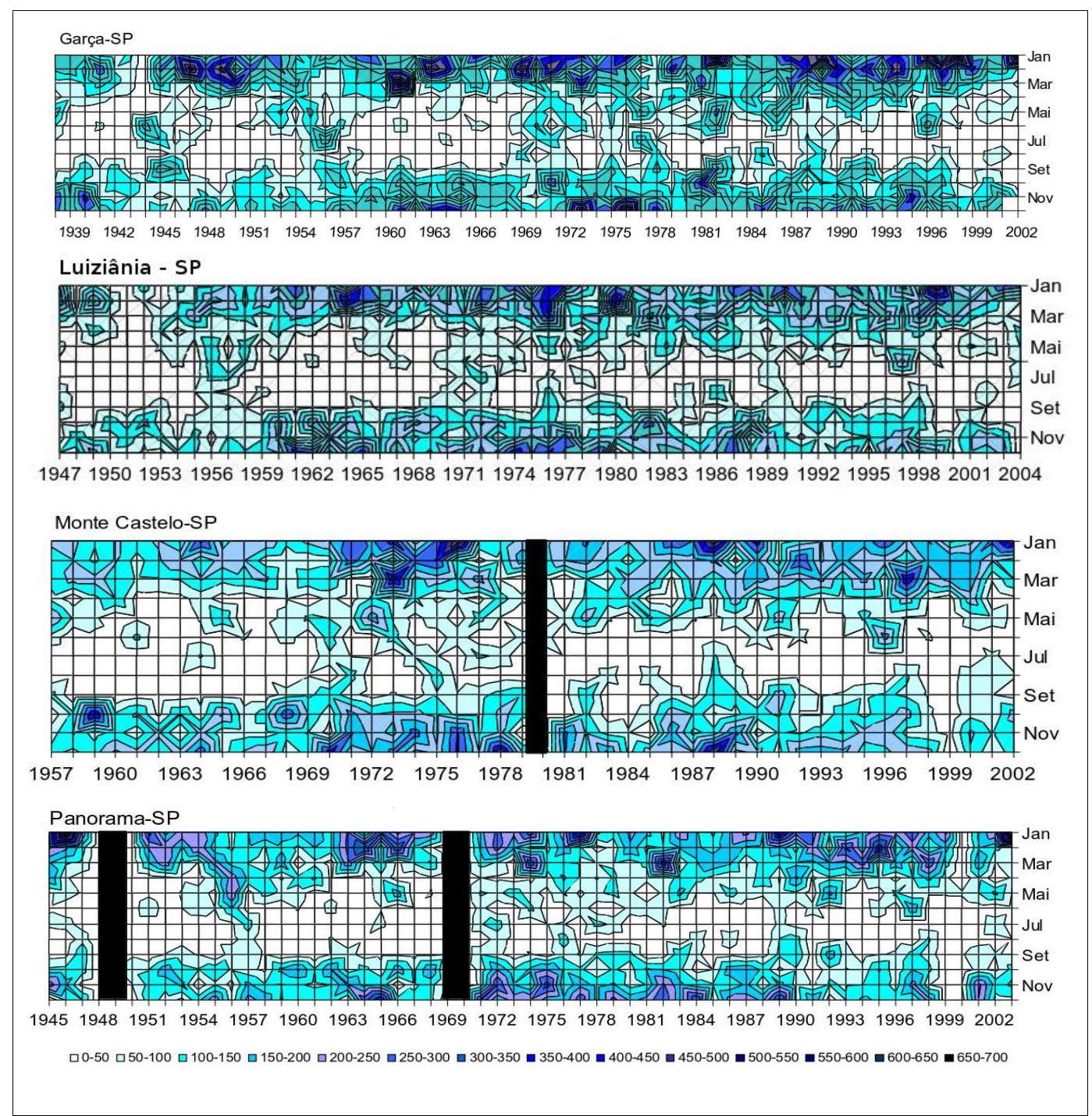

Figura 7. Variabilidade dos totais mensais de chuva em série histórica para Garça, Luiziânia, Monte Castelo e Panorama, região oeste paulista. As tarjas pretas indicam anos com falha nos dados.

Tal fato demonstra o papel da vegetação (retenção de água) no ciclo hidrológico: "...um poço escavado no início da instalação agrícola não enche antes da destruição da floresta; ou de que o riacho em cuja margem construíram-se os primeiros abrigos, passou a correr mais abundantemente quando a floresta foi destruída". A figura 10 (A e B) apresenta a evolução da frente pioneira paulista no início e meados do século XX. 


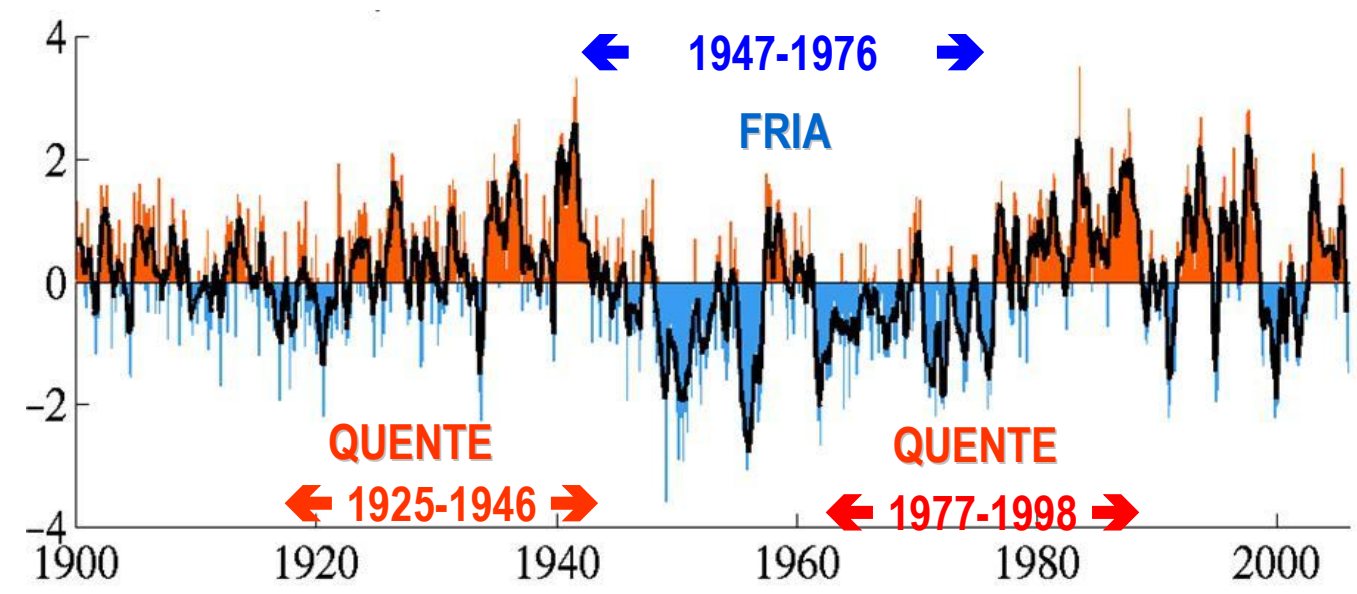

Figura 8. Variação dos índices de Oscilação Decadal do Pacífico (ODP). Fonte: Molion (2008, baseado em Mantua et al., 1997).

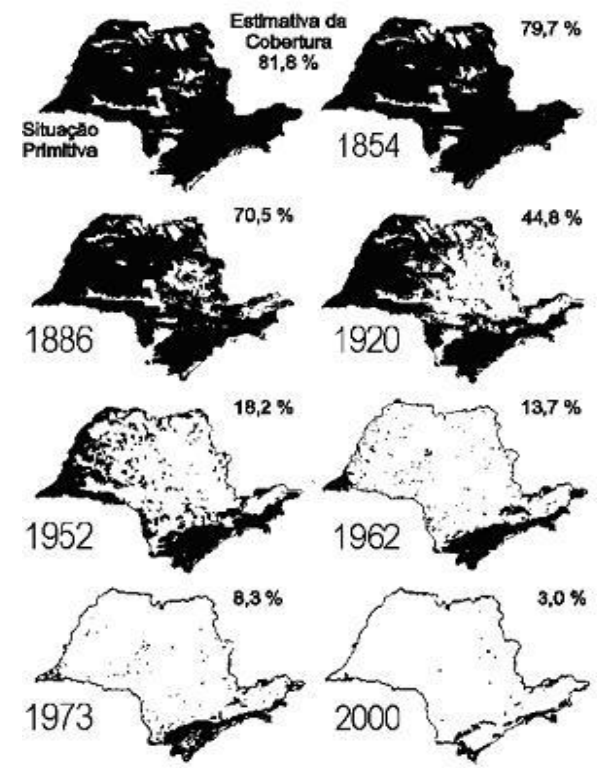

Figura 9. Avanço do desmatamento no estado de São Paulo. Fonte: CAVALLI et al., 1974; RBMA, 2007.

Aumentos na variabilidade hidrológica em sistemas fluviais são comuns em áreas que alternam florestas e agricultura intensiva (DREW, 1994).

Outra intervenção significativa no ciclo hidrológico, com ação direta no regime de fluxo do rio e o controle de débitos efetuado pelos barramentos nas UHEs, necessários para a geração de energia; contudo, neste trabalho os procedimentos utilizados não detectaram alterações causadas por PCHs instaladas na bacia. A esse respeito, oficialmente, apenas a PCH Quatiara, no rio do Peixe é cadastrada no sistema da ANEEL.

É importante o entendimento dos motivos que levaram às alterações e qual a intensidade dos relacionamentos com as alterações nos regimes hidrológicos dos rios. 


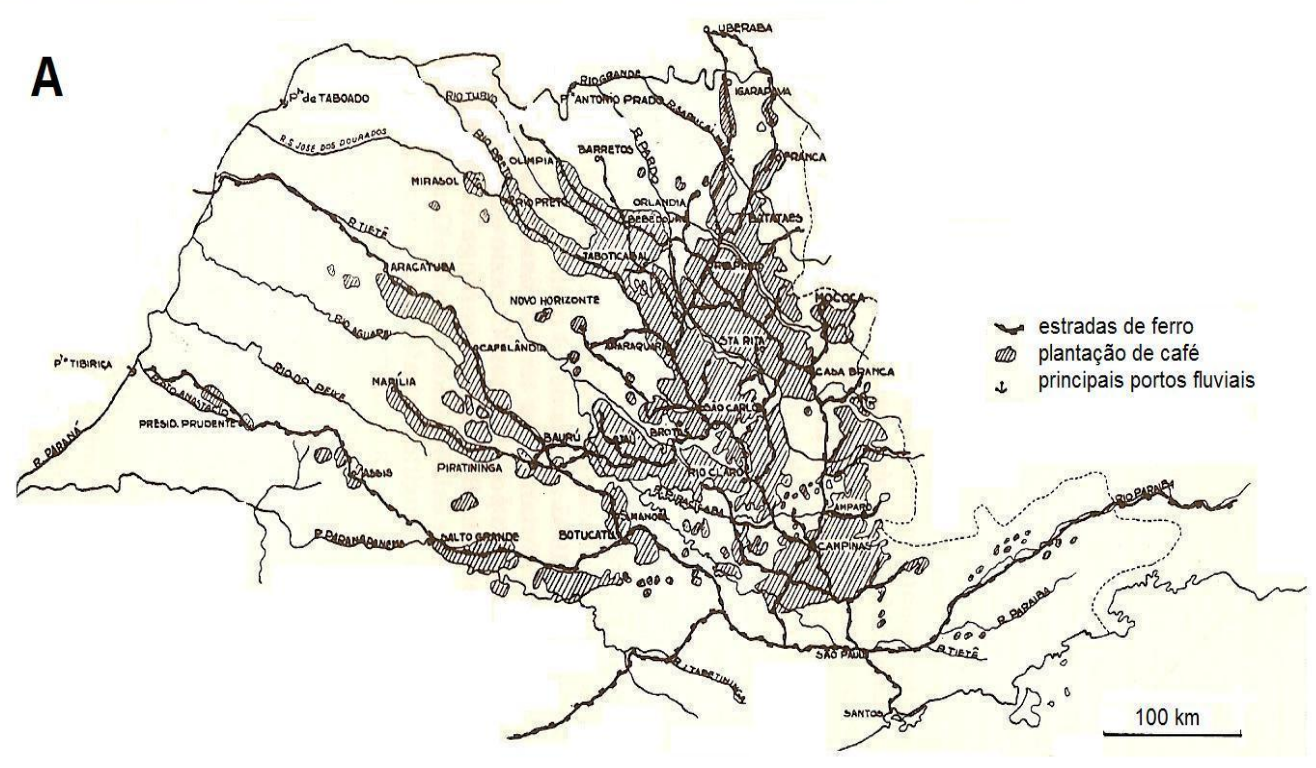

Cultura do café e vias férreas às vésperas da crise de 1929

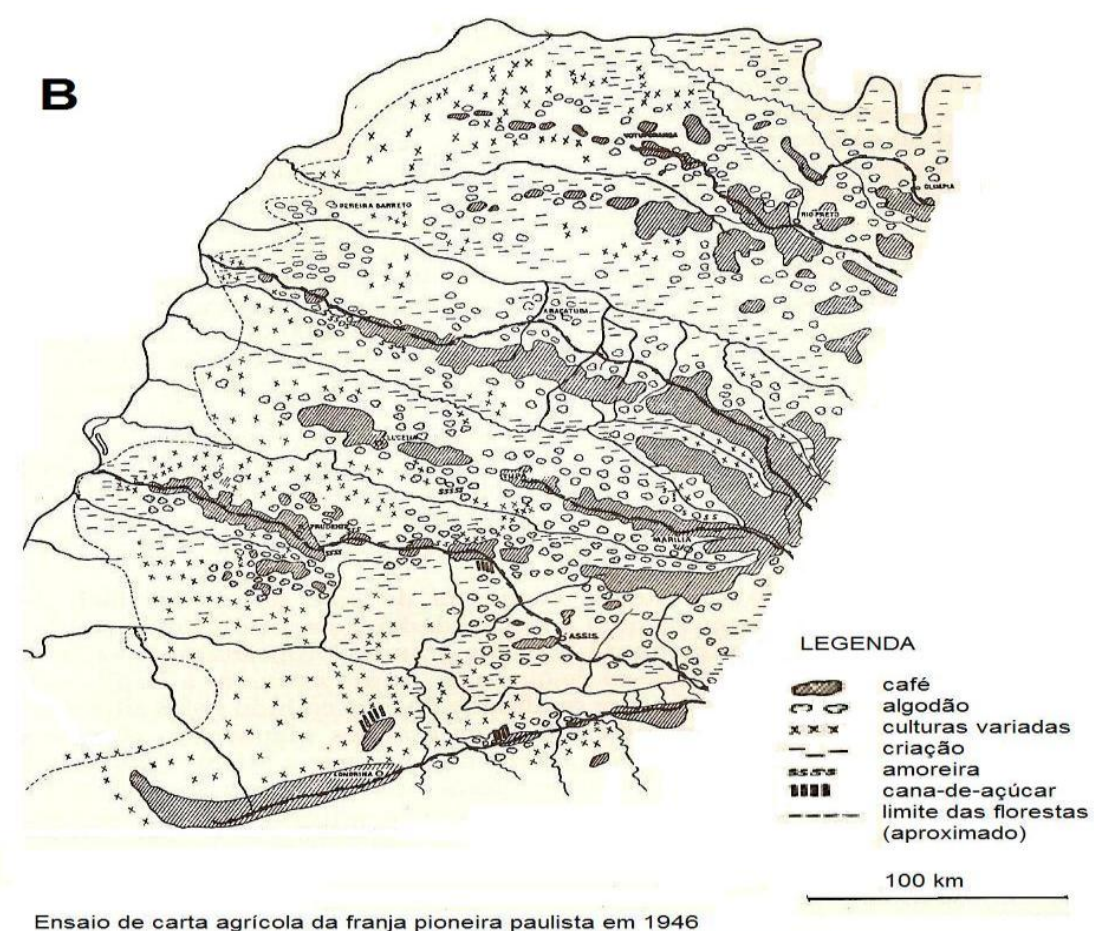

Figura 10. A cultura do café em 1929 (A) e carta agrícola em 1946 (B). Fonte: Monbeig (1984).

Entretanto, há dificuldades na aquisição de dados sistemáticos do comportamento climático e dos processos ocupacionais na bacia hidrográfica, nesta escala espacial, para que se possa estabelecer quais são os processos correlacionados e qual o grau de relacionamento entre as variações nos regimes dos rios, no regime pluviométrico e nos fatores antrópicos do modelo de uso e ocupação, desenvolvidos durante o século $X X$, nesta região.

Os dados de desmatamento e de uso e ocupação das áreas (manejo do solo) parecem manter alguma correlação com a variabilidade climática, dificultando o estabelecimento e entendimento das relações quantitativas para cada uma das causas para as alterações no regime hidrológico destes rios. 
Sendo assim, a opção pela análise qualitativa pode ajudar no entendimento dos processos. Cabe observar o que se pensava à época dos pioneiros do oeste paulista, conforme descrito por Pierre Monbeig em 1949: ...há sem dúvida, entre os agricultores, uma tendência a evocar com emoção as qualidades dos climas do passado, o que não elimina o fato impressionante de haver uma convergência das informações... o que se verifica, realmente, é que as comparações entre os dados climáticos mais antigos e os mais recentes indicam sempre e em toda parte o revigoramento do período seco, que corresponde à diminuição das precipitações do inverno e primavera. Ao contrário, as chuvas de verão são mais abundantes... (MONBEIG, 1984). Tais fatos mostram que as alterações já eram percebidas desde esse período, tiveram continuidade e puderam ser constatadas posteriormente.

Dessa forma, os fatores desmatamento, manejo do solo, alteração no regime pluviométrico (intensidade e sazonalidade) merecem atenção pois, conceitualmente, se relacionam direta ou inversamente com o regime hidrológico do rio.

Os dois primeiros fatores conduzem a intensificação da magnitude do fluxo no rio e alteração na magnitude sazonal. Quanto ao último fator, os dados de aumento da pluviometria conduzem obviamente a aumento na magnitude dos fluxos nos rios; a alteração na sazonalidade também reforça os efeitos sazonais no regime fluvial. Como visto, pode-se esperar que haja alteração no regime hidrológico do rio, tanto do ponto de vista das magnitudes do fluxo, quanto da magnitude sazonal do fluxo.

Os dados pluviométricos e fluviométricos podem ser correlacionados qualitativamente e quantitativamente.

\section{CONSIDERAÇÕES FINAIS}

As alterações interanuais no regime hidrológico dos rios Aguapeí e Peixe parecem ser reflexo de duas componentes: 1) da variabilidade pluviométrica, e possivelmente climática, de modo geral, como processo natural na escala de tempo avaliada; 2) interferências antrópicas alterando a cobertura da terra, com os processos de desmatamento e implementação de vários ciclos de culturas e pecuária.

Tais fatos ainda não puderam ser separados em termos quantitativos, contudo, qualitativamente e conceitualmente pode-se inferir que o desmatamento leva a um aumento no escoamento superficial e isso acarreta maior variabilidade no fluxo do rio. Assim, esta pode ser a alternativa até o momento, para explicar o aumento da variabilidade interanual observada nos fluxos dos rios.

No caso específico do oeste paulista, os ciclos do café/algodão, pastagens, cana-de-açúcar podem ter influenciado nos padrões de variação e caracterização dos períodos hidrológicos observados e merecem uma abordagem mais detalhada num próximo momento.

De modo geral, este estudo corrobora a afirmação de estudos anteriores na bacia do Paraná sobre aumento dos fluxos nos rios a partir da década de 1970. Contudo, pode se observar com maior clareza os períodos hidrológicos produzidos pela variabilidade climática natural, com duração de cerca de 10 a 20 anos em cada período.

O planejamento territorial de uma bacia hidrográfica, com base em princípios ambientais constitui o melhor método para evitar a degradação de seus recursos hídricos e deve ser elaborado através do estudo dos componentes físico, biológico e socioeconômico. Além disso, a Lei Federal $n^{0}$ 9.433, de 8 de janeiro de 1997, que dispõe sobre a Política Nacional de Recursos Hídricos, define a bacia hidrográfica como unidade de planejamento. Esta lei institui os comitês de bacias hidrográficas ( $\mathrm{CBH})$, com a competência de aprovar os planos de recursos hídricos da bacia. Assim são necessárias informações sobre aspectos geológicos e geomorfológicos, características do solo, topografia, condições climáticas e regime hidrológico dos rios.

Dados sobre a cobertura vegetal, especialmente às margens dos recursos hídricos, são importantes, assim como o levantamento dos ecossistemas naturais, principalmente os que interagem com os mananciais. 
A gestão de ecossistemas alagáveis e terrestres, que margeiam rios, precede um reconhecimento dos padrões naturais de regime hidrológico do rio, para que se possa proceder uma estratégia eficiente de manejo ambiental. Do mesmo modo, a identificação de alterações no regime de fluxo natural, pode ser um instrumento eficiente na tomada de decisão quanto às estratégias para a mitigação dos impactos nos ecossistemas adjacentes, além de colaborar para a identificação de alterações climáticas, nos processos desencadeados nas vertentes (uso e ocupação) ou na própria rede hidrográfica (como a operação nas hidroelétricas).

O primeiro passo a ser dado no rumo certo do planejamento dos recursos hídricos é incorporar os estudos (entendimento) dos regimes de fluxos dos rios e suas alterações nas estratégias de manejo e reconhecer que uma alteração extensiva foi imposta pelas ações humanas no fluxo do rio, que resultaram em intensas mudanças geomórficas e ecológicas nestes sistemas além de problemas de abastecimento público e saneamento.

\section{AGRADECIMENTOS}

Os autores agradecem ao CNPq pelo apoio financeiro ao projeto de pesquisa, processo: 477564/2010-0, Edital MCT/CNPq 14/2010.

\section{REFERÊNCIAS BIBLIOGRÁFICAS}

.ARAUJO, A.P., ROCHA, P.C. \& BOTA, G.B. Variabilidade do regime de fluxo do rio Pardo, bacia do médio Paranapanema. XVIII Simpósio Brasileiro de Recursos Hídricos, Campo Grande-MS, 2009.

.CAVALLI, A. C., GUILLAUMON JR, R.; SERRA FILHO R. Levantamento da cobertura vegetal e do reflorestamento no estado de São Paulo. Boletim Técnico do Instituto Florestal, São Paulo, v.11.,1974.

.CLARKE, R. T., TUCCI, C. E. M., COLLISCHONN, W. Variabilidade temporal no regime hidrológico da bacia do rio Paraguai. Revista Brasileira de Recursos Hídricos. Vol. 8 n 1 jan mar p. 201-211. 2003.

.COLLISCHONN, W, TUCCI, C.E.M. \& CLARKE, R.T., 2001. Further evidence of changes in the hydrological regime of the Paraguay River: part of a wider phenomenon of climate change?. Journal of Hydrology 245, 218-238.

.DREW, D., 1994. Processos interativos homem-meio ambiente. Bertrand Brasil. $3^{\mathrm{a}}$. ed. Rio de Janeiro.

.IPT - INSTITUTO DE PESQUisAs TECNOLÓGICAS DO ESTAdO DE SÃO PAULO. Mapa geológico do Estado de São Paulo; escala 1:500.000. v1 (texto) e v2 (mapa). Governo do estado de São Paulo. Secretaria da Indústria, Comércio, Ciência e Tecnologia.1981.

Spec. Public. Fish. Aquat. Sci., 106. 110-127 pp.

.MOLION, L.C.B., 2008. Perspectivas climáticas para os próximos 20 anos. Revista Brasileira de Climatologia. ABClima. Vol. 2/4, ano 4. Presidente Prudente-SP.

.MOLION, L.C.B., 2008. Aquecimento global: uma visão crítica. Revista Brasileira de Climatologia. ABClima. Vol. 2/4, ano 4. Presidente Prudente-SP.

.MONBEIG, P., 1984. Pioneiros e fazendeiros de São Paulo. Ed. Hucitec. Sao Paulo. 392p. .MONTEIRO, C.A.F. A dinâmica climática e as chuvas do estado de São Paulo: estudo geográfico sob forma de atlas. São Paulo: IGEOG, 1973.

.NEIFF, J.J., 1990. Ideas para la interpretacion ecologica del Parana. Interciencia, vol 15, n. 6. 424-440 pp.

.PETTS, G. \& FOSTER, I., 1990. Rivers and landscape. The Athenaeum Press, 3 ed., New Castle, Great Britain. 
.POFF, H.L., ALLAN, D., BAIN, M.B., KARR, J.R., PRESTEGAARD, K.L., RICHTER, B.D., SPARKS, R.E., \& STROMBERG, J.C., 1997. The natural flow regime: a paradigm for river conservation and restoration. Bioscience, vol. 47, n. 11. P. 769-784.

.RBMA ORG 2007. Site www.rbma.org, acesso dia 04/06/2007.

.RICHTER, B.D., BAUMGARTNER, J.V., WIGINGTON, R. \& BRAUN, D.P., 1997. How much water does a river need. Freshwater Biology, 37. 231-249 p.

.ROCHA, P.C., 1997. Aspectos fisiográficos da planície aluvial do alto Rio Paraná, entre Porto Primavera-MS e Porto 18-PR. VII Encontro Sul-Mato-Gross. de Geógrafos. Três LagoasMS. Anais.

.ROCHA, P.C., 2010. Indicadores de alteração hidrológica no alto rio Paraná: intervenções. Sociedade \& Natureza, Uberlândia, 22 (1): 205-225.

.ROCHA, P.C.; FERNANDEZ, O.V.Q.; SOUZA FILHO, E.E., 1994. Influência de grandes barragens sobre o regime hidrológico do Rio Paraná em Guaíra-PR. An. $5^{\circ}$ Cong. Bras. de Geógrafos, Curitiba-PR. Boletim de resumos.

.ROCHA, P.C.; FERNANDEZ, O.V.Q.; SOUZA FILHO, E.E., 1995. Abrangência de enchentes sobre a planície aluvial do Rio Paraná entre Porto Primavera-MS e Porto Camargo-PR. VIII Congr. Nac. ABEQUA. Boletim de resumos.

.ROCHA, P.C., SANTOS, M.L. \& SOUZA FILHO, E.E., 2001. Alterações no regime hidrológico do alto rio Paraná como resposta ao controle de descargas efetuado por grandes barramentos a montante. VIII Encuentro de Geógr. de América Latina, Santiago-Chile, pp 28-39.

.ROCHA, P.C., SOUZA FILHO, E.E \& FERNANDEZ, O.V.Q., 1998. Aspectos do controle de descargas efetuado por barramentos no alto rio Paraná. Boletim Paranaense de Geociências 46. Curitiba-Pr-Brasil, pp 117-122.

.ROCHA, P.C., COMUNELLO, E., SOUZA FILHO, E.E. Considerações sobre a variabilidade hidrológica do alto rio Paraná. Geo UERJ, Rio de Janeiro, ed. esp., p.2022-2031, 2003.

.ROSS, J. L. S. e MOROZ, I. C. Mapa geomorfológico do estado de São Paulo. São Paulo, DG-FFLCH-USP, IPT, FAPESP, 1997.

.SANT'ANNA NETO, J.L., 2000. As chuvas no estado de São Paulo: a variabilidade pluvial nos últimos 100 Anos. In: Sant'Anna Neto, J.L. \& Zavatini, J.A. (orgs), Variabilidade e mudanças climáticas. Eduem, Maringá-PR.

.TUCCI, C.E.M \& CLARKE, R.T., 1998. Environmental issues in the La Plata basin. Water resources development, 4 (2), 157-173.

.ZAVATINI, J.A., 1998. Anos secos e anos chuvosos na bacia do Paraná. IX Encontro SulMato-Grossense de Geógrafos. Três Lagoas-MS. 